\title{
NEUROPHYSIOLOGIC ASSESSMENT OF NERVE IMPAIRMENT IN POSTEROLATERAL AND MUSCLE-SPARING THORACOTOMY
}

\author{
Fabrizio Benedetti, MD ${ }^{\mathrm{a}, \mathrm{b}}$ \\ Sergio Vighetti, $\mathrm{PhD}^{\mathrm{a}, \mathrm{c}}$ \\ Claudia Ricco, $\mathrm{MS}^{\mathrm{a}}$ \\ Martina Amanzio, MS ${ }^{\mathrm{a}, \mathrm{b}}$ \\ Luciana Bergamasco, $\mathrm{PhD}^{\mathrm{c}}$ \\ Caterina Casadio, $\mathrm{MD}^{\mathrm{d}}$ \\ Roberto Cianci, $\mathrm{MD}^{\mathrm{d}}$ \\ Roberto Giobbe, $\mathrm{MD}^{\mathrm{d}}$ \\ Alberto Oliaro, $\mathrm{MD}^{\mathrm{d}}$ \\ Bruno Bergamasco, $\mathrm{MD}^{\mathrm{a}, \mathrm{c}}$ \\ Giuliano Maggi, $\mathrm{MD}^{\mathrm{d}}$
}

\begin{abstract}
Objective: This study was aimed at analyzing the degree of intercostal nerve impairment in posterolateral and muscle-sparing thoracotomy and at correlating the nerve damage to the severity of long-lasting postthoracotomy pain. Methods: Neurophysiologic recordings were performed 1 month after either posterolateral or muscle-sparing thoracotomy to assess the presence of the superficial abdominal reflexes (mediated in part by the intercostal nerves), the somatosensory-evoked responses after electrical stimulation of the surgical scar, and the electrical thresholds for tactile and pain sensations of the surgical incision. Results: The patients who underwent a posterolateral thoracotomy showed a higher degree of intercostal nerve impairment than the muscle-sparing thoracotomy patients as revealed by the disappearance of the abdominal reflexes, a larger reduction in amplitude of the somatosensory-evoked potentials, and a larger increase of the sensory thresholds to electrical stimulation for both tactile perception and pain. In addition, these neurophysiologic parameters were highly correlated to the postthoracotomy pain experienced by the patients 1 month after surgery, indicating a causal role for nerve impairment in the long-lasting postoperative pain. Conclusions: This study shows for the first time the pathophysiologic differences between posterolateral and musclesparing thoracotomy and suggests that the minor long-lasting posthoracotomy pain in muscle-sparing thoracotomy patients is partly due to a minor nerve damage. In addition, because nerve impairment is responsible for the long-lasting neuropathic component of postoperative pain, it is necessary to match specific treatments to the neuropathic pain-generating mechanisms. (J Thorac Cardiovasc Surg 1998;115:841-7)
\end{abstract}

Lpro ong-lasting and distressing pain is often a serious problem for those patients who undergo thoracotomy. Several lines of evidence suggest that postthoracotomy pain lasting for months might be due to intercostal nerve impairment so as to produce an important neuropathic component of postoperative pain. ${ }^{1-4}$ Nerve damage also appears to play an important role in pain perception soon after opera-

From the Department of Neuroscience, ${ }^{\text {a }}$ CIND Center for the Neurophysiology of Pain, ${ }^{\mathrm{b}}$ Center for Brain Electrical Activity Mapping, ${ }^{c}$ Department of Thoracic Surgery, ${ }^{\text {d }}$ University of Torino Medical School, Torino, Italy.

Received for publication August 4, 1997; revisions requested Oct. 14, 1997; revisions received Oct. 30, 1997; accepted for publication Nov. 4, 1997.

Address for reprints: Fabrizio Benedetti, Dipartimento di Neuroscienze, Università di Torino, Corso Raffaello 30, 10125 Torino, Italy.

Copyright (C) 1998 by Mosby, Inc.

$0022-5223 / 98 \$ 5.00+0 \quad \mathbf{1 2 / 1 / 8 7 3 5 4}$ tion. ${ }^{3}$ In particular, we have recently shown that if superficial abdominal reflexes (which are mediated in part by the inferiormost intercostal nerves) are absent after posterolateral thoracotomy, postoperative pain intensity is higher and opioid treatments less effective. ${ }^{4}$ In addition, the patients who do not show any recovery of abdominal reflexes 2 to 3 months after operation are more likely to complain of pain.

Intercostal nerve impairment and postoperative pain intensity are certainly related to the trauma produced by the operative procedure. For example, posterolateral thoracotomy is very traumatic and induces severe pain. ${ }^{4-6}$ By contrast, muscle-sparing thoracotomy causes less pain and fewer complications. ${ }^{6-13}$ This is because muscle-sparing thoracotomy approaches the lung through the auscultatory triangle with a relatively small skin incision and no resection of the muscles. On the basis of these considerations, we decided to assess the degree of 
a

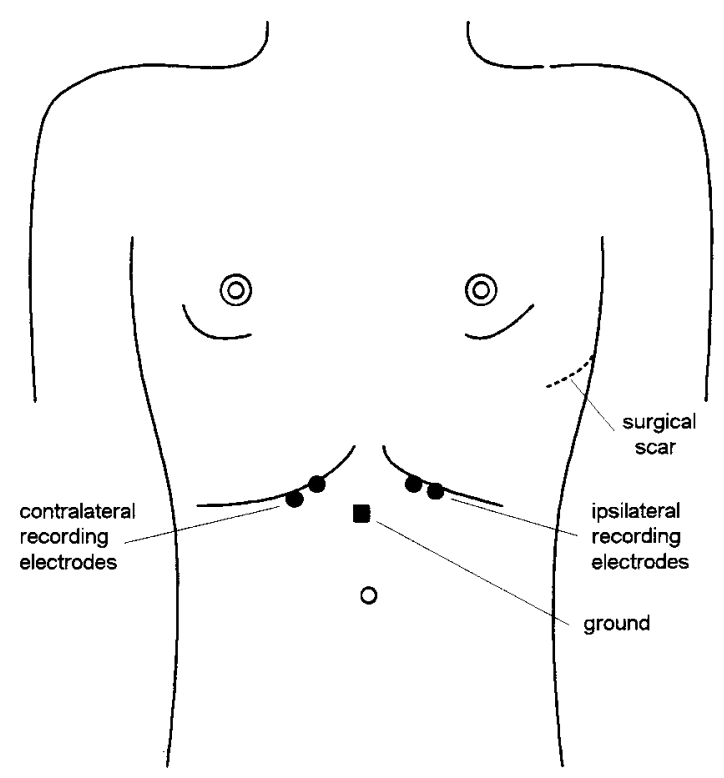

b

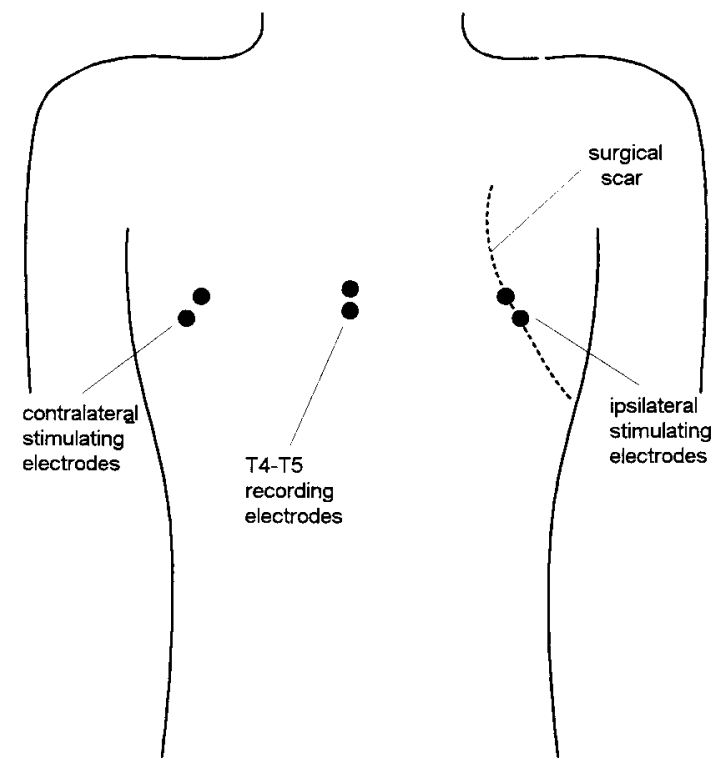

Fig. 1. Paradigm of electrophysiologic recording of the superficial abdominal reflexes (a) and the thoracic somatosensory-evoked potentials (b). In a the stimulus was represented by mechanical scratching of the abdominal wall.

intercostal nerve impairment in posterolateral and muscle-sparing thoracotomy by means of electromyography (EMG) and somatosensory-evoked potentials (SEP) and by assessing tactile and pain thresholds to electrical stimulation on the operative scar.

\section{Patients and methods}

This study was performed in 24 patients who gave informed consent for electrophysiologic recordings. Standard posterolateral thoracotomy was performed in 11 patients (seven men and four women with a mean age of $54.3 \pm 8.7$ years SD and a mean weight of $62.9 \pm 6.9 \mathrm{~kg}$ $\mathrm{SD})$; muscle-sparing thoracotomy was performed in 13 patients (seven men and six women with a mean age $58.5 \pm 11.1$ years SD and a mean weight $57.4 \pm 9.2 \mathrm{~kg}$ $\mathrm{SD})$. All thoracotomies were performed through the fifth or sixth intercostal space. Patients with a history of previous thoracotomy were excluded. Standard posterolateral thoracotomy was performed by transecting either the latissimus dorsi and serratus anterior $(n=5)$ or the latissimus dorsi and trapezius $(n=6)$ through a skin incision averaging $18.6 \pm 4.7 \mathrm{~cm}$ SD. In muscle-sparing thoracotomy no muscle was cut, and the lung was approached through the auscultatory triangle, with a skin incision averaging $13.2 \pm 3.2 \mathrm{~cm}$ SD. In all cases lung resection consisted of a segmentectomy, and in no case did rib fracture occur. Diagnosis was either primary lung carcinoma (four posterolateral thoracotomy patients and seven muscle-sparing thoracotomy patients) or metastatic disease (seven posterolateral and six muscle-sparing).

About 1 month after surgery, the patients were tested for the presence of the superficial abdominal reflexes through EMG recording, the thoracic evoked potentials after electrical stimulation of the operative scar, and the sensory thresholds to electrical stimulation of the operative incision. In addition, the presence of postthoracotomy pain was assessed by means of a numerical rating scale ranging from $0=$ no pain to $10=$ unbearable pain and a visual analog scale (VAS) ranging from $0 \mathrm{~mm}=$ no pain to $100 \mathrm{~mm}=$ unbearable pain.

The recording of the superficial abdominal reflexes (EMG) has already been described by Benedetti and colleagues. ${ }^{4}$ Briefly, recording electrodes were placed on both abdominal walls, ipsilateral and contralateral to the thoracotomy, in the very superior portion of the abdomen (Fig. 1,a). Mechanical stimulation was performed by means of a needle scratching the skin of the abdomen in the lateral-medial direction. The signal from the recording electrodes was amplified and sent to a storage oscilloscope for subsequent analysis of the amplitude and duration of the EMG responses. In this way we could test the superficial abdominal reflexes ipsilateral and contralateral to the thoracotomy.

The SEP were evoked by stimulating the operative scar. To do this, two stimulating electrodes $(5 \mathrm{~mm}$ in diameter) were placed on the surgical scar and two other electrodes were placed on the normal skin of the opposite side for control (Fig. 1, b). Electrical stimuli were delivered through a constant current unit, thus avoiding the variability of skin-electrode impedance. The two recording electrodes (diameter: $5 \mathrm{~mm}$ ) were positioned on the skin overlying the spinal cord at the level of the same dermatome of the stimulating electrodes (either T4 or T5) and the signal was amplified and sent to a computer for averaging. Stimulation was performed at a frequency of five stimuli per second, the duration of which was 200 $\mu$ sec, and the final evoked potential was obtained by averaging 150 to 200 responses. To avoid variability 
between the two groups, we analyzed only a negative response with a latency of $8 \mathrm{msec}$ (wave N8), which was constant in all subjects. N8-evoked responses to operative scar stimulation were compared with N8 responses after stimulation of the normal skin of the opposite side.

During electrical stimulation we also tested both tactile and pain thresholds. In fact, we asked the patients to report when they felt the stimulus (tactile threshold to electrical stimulation) and when the stimulus became painful (threshold of pain to electrical stimulation). To do this, a series of increasing and decreasing stimuli were randomly delivered to the patient with steps of $1 \mathrm{~mA}$. Randomization of stimulus intensities was generated by a computer. Both the operative scar and the normal skin of the opposite side were analyzed.

Statistical analysis was performed by means of the Mann-Whitney U test ( $z$ value) when the differences between contralateral and ipsilateral responses were considered. The data are shown as the percentage of ipsilateral EMG or SEP responses and sensory thresholds relative to the contralateral responses and thresholds. In this way we overcame the variability among different subjects. The amplitude of the abdominal reflexes was measured by considering the mean of the first three responses to needle stimulation because habituation occurred very quickly in some patients. In addition, analysis of variance for skin incision length and VAS and linear regression analysis were performed. Data are presented as the mean \pm standard deviation.

\section{Results}

The two groups who had posterolateral and muscle-sparing thoracotomy did not differ for sex, age, weight, and type of lung resection. By contrast, besides the difference in muscle resection, the skin incision was different in the two groups $(F[1,22]=$ 11.12, $p=0.003$ ), as already described in Patients and methods.

Recording of the superficial abdominal reflexes 1 month after operation showed that in 7 of 11 posterolateral thoracotomy patients $(63.6 \%)$ and in only 1 muscle-sparing thoracotomy patient $(7.7 \%)$ the ipsilateral EMG responses were completely absent. Fig. 2 shows the percentage of variation of the ipsilateral abdominal EMG responses relative to the contralateral responses in both groups. The mean reduction in amplitude of the abdominal reflexes was $-64.6 \% \pm 49.4 \%$ SD for posterolateral thoracotomy patients and $-5.3 \% \pm 31.9 \%$ SD for musclesparing thoracotomy patients $(z=2.564, p=0.01)$. In particular, it should be noted that most of the muscle-sparing thoracotomy patients (except one patient) showed ipsilateral reflexes equal to the contralateral ones.

The results obtained with the thoracic SEP were very similar to those found with the EMG analysis.

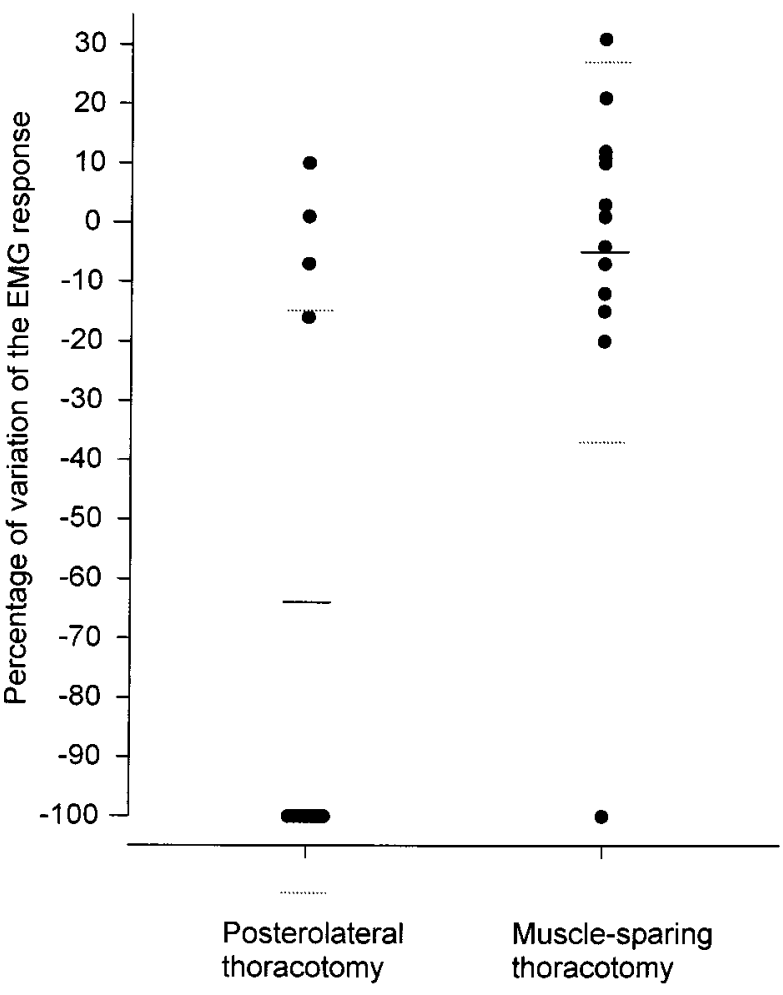

Fig. 2. Percentage variation of the amplitude of abdominal reflexes ipsilateral to the operative scar relative to the contralateral side in posterolateral and muscle-sparing thoracotomy patients.

In fact, Fig. 3 shows that the percentage of variation of the ipsilateral $\mathrm{N} 8$ amplitude after a $10 \mathrm{~mA}$ stimulation of the operative scar was much higher in posterolateral thoracotomy patients than in musclesparing thoracotomy patients relative to the N8 response after stimulation of the contralateral normal skin. The mean N8 amplitude reduction was $-37.8 \% \pm 15.4 \%$ SD for posterolateral thoracotomy patients and $-14.6 \% \pm 16.3 \%$ SD for muscle-sparing thoracotomy patients $(z=2.897, p=0.004)$. A similar difference was present by increasing the stimulus intensity to $15 \mathrm{~mA}$ (not shown). We could not compare ipsilateral and contralateral stimulation for intensities greater than $15 \mathrm{~mA}$ because the patients complained of a painful sensation when stimulated on the contralateral normal skin. However, we could increase the stimulus intensity up to $40 \mathrm{~mA}$ and beyond when the operative scar was stimulated in posterolateral but not muscle-sparing thoracotomy patients, indicating that hypesthesia was greater after posterolateral thoracotomy.

A detailed analysis of tactile and pain thresholds 


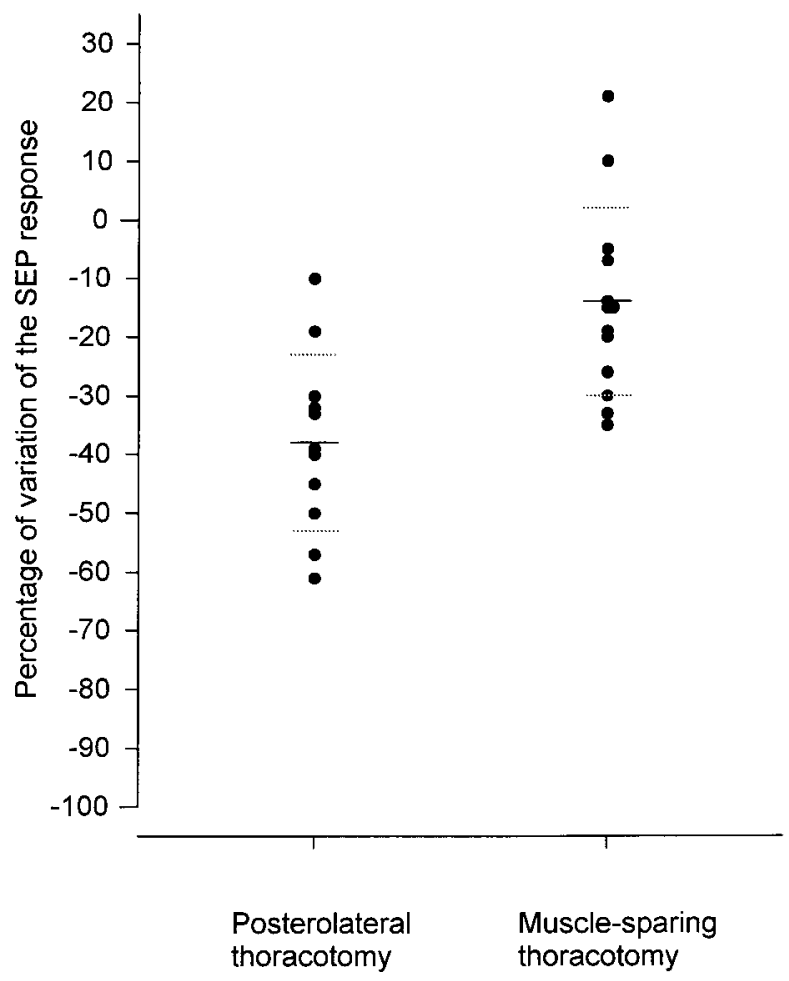

Fig. 3. Percentage variation of the amplitude of somatosensory-evoked potential after stimulation of the operative scar relative to the contralateral side in posterolateral and muscle-sparing thoracotomy patients.

to electrical stimulation is shown in Fig. 4. We found a clear-cut difference between posterolateral and muscle-sparing thoracotomy for both tactile and pain thresholds. In both groups the thresholds for tactile and pain perception after electrical stimulation of the surgical scar were much higher compared with those tested on the contralateral normal skin. However, whereas in posterolateral thoracotomy patients the percentage increase was $357.7 \% \pm$ $130.2 \%$ SD for tactile threshold and $172.5 \% \pm$ $29.4 \%$ SD for pain threshold, in muscle-sparing thoracotomy patients the increase was $194.3 \% \pm$ $109.5 \%$ SD for tactile threshold and $109.8 \% \pm$ $37.2 \%$ SD for pain $(z=2.839, p=0.005$ for tactile threshold and $z=3.422, p=0.0005$ for pain threshold). Thus, although the skin of the operative scar was hypesthesic and hypalgesic in both groups 1 month after operation, the hypesthesia and hypalgesia were less pronounced in muscle-sparing compared with posterolateral thoracotomy patients, indicating only minor nerve damage after a musclesparing thoracotomy.

As far as spontaneous postthoracotomy pain is

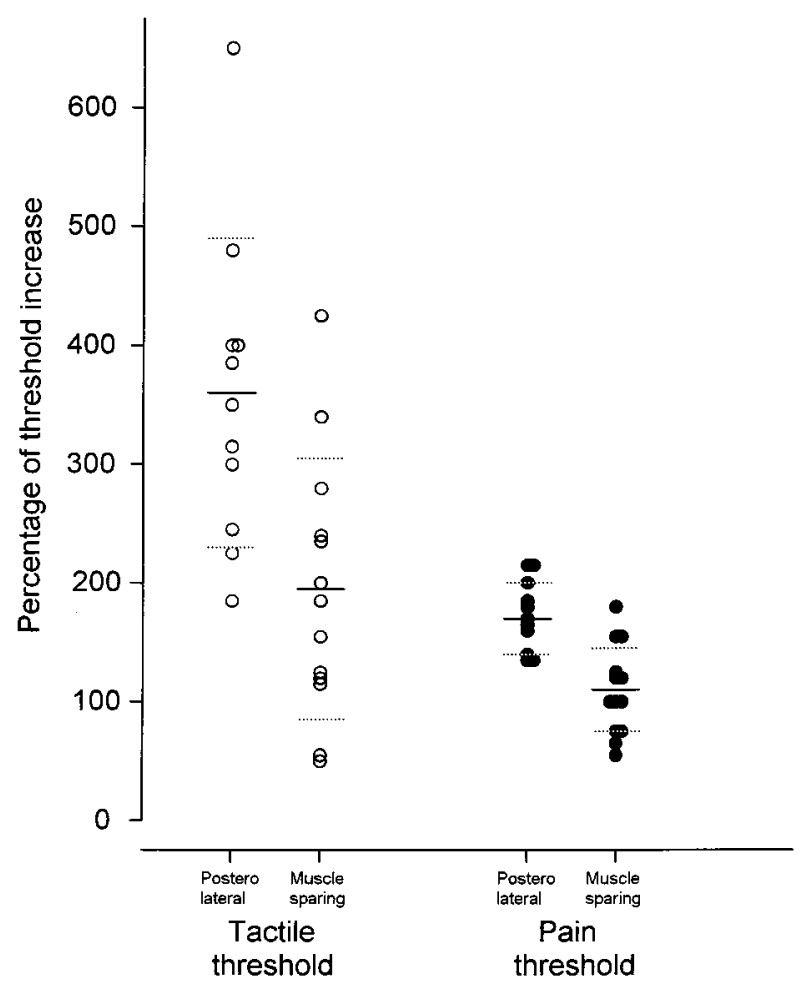

Fig. 4. Percentage increase in tactile and pain thresholds to electrical stimulation of the operative scar after posterolateral and muscle-sparing thoracotomy.

concerned, we found a significant difference in pain experience between the two groups 1 month after surgery. In fact, whereas the mean VAS was $21 \pm$ 17.67 SD for posterolateral thoracotomy patients, it was $5.85 \pm 8.11 \mathrm{SD}$ for muscle-sparing thoracotomy patients $(F[1,22]=7.7, p=0.01)$. Thus the two groups differed for EMG and SEP responses, tactile and pain electrical thresholds, and postthoracotomy pain intensity.

Because we recently demonstrated that the presence or absence of the superficial abdominal reflexes are related to pain intensity, ${ }^{4}$ we also wanted to test whether SEP responses and tactile-pain thresholds were related to the VAS scores of spontaneous postthoracotomy pain. To do this, we carried out a statistical analysis within the two groups. It can be seen in Fig. 2, 3, and 4 that the variability within one group (either posterolateral or musclesparing) was high. For example, EMG responses ranged from 0 to normal amplitudes in both groups (Fig. 2). Similarly, in muscle-sparing thoracotomy patients tactile thresholds to electrical stimulation ranged from an increase of about $50 \%$ to more than 
$400 \%$ (Fig. 4). To correlate this individual variability among patients who underwent the same operative procedure, we performed a linear regression analysis between the postthoracotomy pain experienced by the patients on the day of the electrophysiologic recordings and EMG responses, SEP responses, and tactile thresholds to electrical stimulation. The intensity of the postthoracotomy pain within the two groups was correlated to the EMG reduction (as already shown by Benedetti and colleagues ${ }^{4}$ ), SEP reduction, and tactile threshold increase, as shown in Fig. 5. In both groups of patients, postthoracotomy pain intensity (measured with VAS) was high when EMG responses were absent $(r=-0.745, t=$ $-3.350, p=0.009$ for posterolateral and $r=-0.741$, $t=-3.664, p=0.004$ for muscle-sparing) (Fig. 5, $a$ ). The same correlation was present for the amplitude of N8 response $(r=-0.743, t=-3.335, p=0.009$ for posterolateral and $r=-0.649, t=-2.826, p=0.01$ for muscle-sparing) (Fig. 5, b). Similarly, postthoracotomy pain was more pronounced when tactile threshold to electrical stimulation was high, as shown in Fig. 5, $c(r=0.729, t=3.199, p=0.01$ for posterolateral and $r=0.765, t=3.939, p=0.002$ for muscle-sparing). Thus, besides the differences between the two groups, the variability within one group (posterolateral or muscle-sparing) was represented by a strict correlation between postoperative pain and neurophysiologic parameters.

\section{Discussion}

Although several studies demonstrated that muscle-sparing thoracotomy is less painful than posterolateral ${ }^{6-13}$ thoracotomy, we have little information on the pathophysiologic basis of this difference. In this study we were mainly interested in analyzing postthoracotomy pain lasting for several weeks after operation and in assessing the role of nerve damage as the cause of the long-lasting pain. It should be emphasized that postthoracotomy pain is often present for several weeks and months and represents a serious problem for many patients. ${ }^{14}$ It frequently shows the features of neuropathic pain. ${ }^{2}$ The impairment of the intercostal nerves during operation appears to be the most likely factor responsible for the appearance of neuropathic pain. For instance, stretching or damage of the intercostal nerves, transection of their cutaneous branches, and trauma produced by muscle resection and rib retractors may contribute to the development of an important neuropathic component of postoperative pain. Thus posterolateral thoracotomy and muscle-
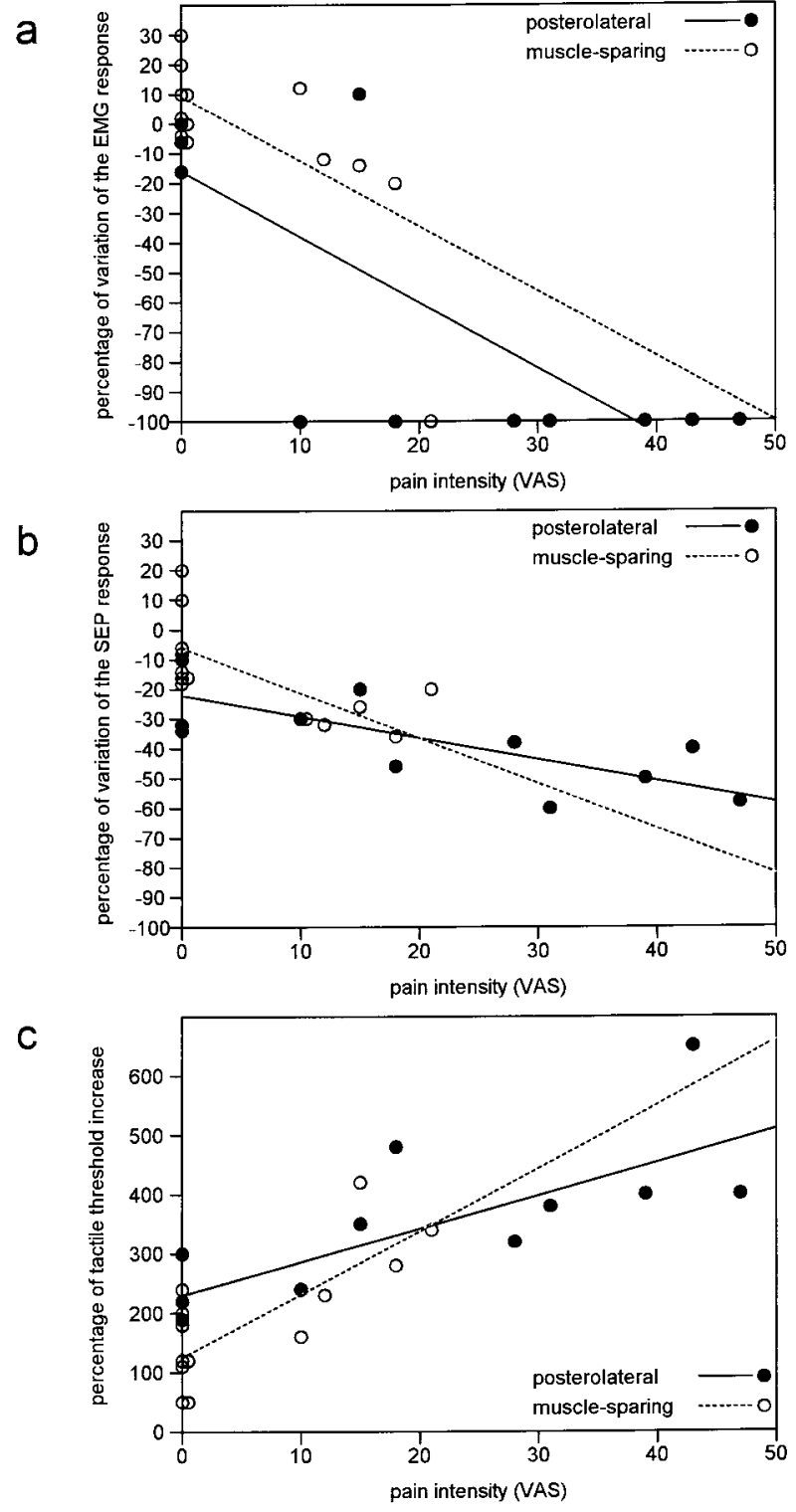

Fig. 5. Correlation between postthoracotomy pain (visual analog scale scores) and abdominal reflexes (a), somatosensory-evoked potentials (b), tactile thresholds to electrical stimulation (c) in posterolateral (filled circles and bold line) and muscle-sparing thoracotomy patients (empty circles and broken line). In $\mathbf{a}$ and $\mathbf{b}$, the higher the pain intensity the smaller the amplitude of the responses. In c, the higher the pain intensity the higher the tactile threshold.

sparing thoracotomy represent two striking examples of operative procedures with different degrees of trauma.

The findings of this study show for the first time that these two operative procedures indeed produce 
a different degree of nerve impairment. As already shown by Benedetti and colleagues ${ }^{4}$ the lack of the superficial reflexes of the superior portion of the abdomen represents a good index of intercostal nerve damage and is strictly correlated to postoperative pain intensity and opioid consumption. By extending these previous observations to the muscle-sparing thoracotomy, it appears evident that EMG responses were unchanged when the muscles were spared (except one patient). By contrast, most of the patients with the standard posterolateral approach showed the disappearance of the superficial abdominal reflexes. A larger reduction in amplitude of the response was also observed at the level of the thoracic SEP in posterolateral compared with muscle-sparing thoracotomy patients, suggesting a larger denervation of the operative scar after posterolateral thoracotomy. The damage to the cutaneous branches of the intercostal nerves was confirmed by measures of tactile and pain thresholds to electrical stimulation. Again, both thresholds were found to be much higher in posterolateral than in muscle-sparing thoracotomy patients. Overall, these neurophysiologic data indicate that the intercostal nerves and their branches show a higher degree of impairment 1 month after posterolateral thoracotomy compared with muscle-sparing thoracotomy.

Although these results shed light on the pathophysiologic basis of two different operative procedures, they also have important clinical implications. In fact, one of the most important findings of this study was represented by the correlation between the neurophysiologic analysis and the intensity of postthoracotomy pain measured by means of VAS. In other words EMG and SEP responses and tactile electrical thresholds were strictly related to the pain experienced by the patients after 1 month; if pain was present, EMG and SEP amplitudes were low or absent and tactile thresholds to electrical stimulation of the operative scar were high. This was true for both the posterolateral and the muscle-sparing thoracotomy patients as revealed by the regression analysis within a single group (Fig. 5). This correlation suggests a causal role of nerve impairment, as assessed through the neurophysiologic measurements, in postthoracotomy pain experienced several weeks after operation. In particular, it should be pointed out that the appearance of this neuropathic component of pain may represent a very important difference between posterolateral and muscle-sparing thoracotomy.

The clinical implications of these data are seen in the pain management required when important nerve impairment has been found. For example, it has been known for a long time that neuropathic pain is less responsive to opioids than nociceptive pain, ${ }^{15-17}$ although adequate analgesia can be obtained by increasing the doses. ${ }^{18-22}$ Similarly, neuropathic pain is particularly sensitive to treatments such as transcutaneous electrical nerve stimulation, neurolysis, tricyclic antidepressants, and lidocaine. ${ }^{23}$ Recently we found that postthoracotomy neuropathic pain can be treated adequately with buprenorphine if the appropriate doses are used, ${ }^{22}$ indicating that opioids must be titrated to an endpoint represented by either adequate analgesia or intolerable side effects.

Therefore, although the pain of a thoracotomy may arise from multiple sources, including inflammation of the chest wall, incision of the pulmonary parenchyma and pleura, and drainage tubes ${ }^{24}$ the impairment of the intercostal nerves must always be considered. With this concept in mind, adequate treatment of those forms of postoperative pain where nerve damage plays an important role is possible.

\section{Conclusions}

Neurophysiologic assessment of abdominal reflexes, SEP, and sensory thresholds to electrical stimulation of the operative scar revealed that muscle-sparing thoracotomy produced less intercostal nerve impairment than posterolateral thoracotomy. The nerve damage was associated with the presence of postthoracotomy pain 1 month after operation that was more severe in posterolateral compared with muscle-sparing thoracotomy patients This indicates that one of the most important differences between the two operative procedures is represented by the neuropathic component of postoperative pain. These findings clarify the pathophysiology of postthoracotomy pain and allow an adequate pain management aimed at targeting specific paingenerating mechanisms.

\section{REFERENCES}

1. Tasker RR, Tsuda T, Hawrylyshyn P. Clinical neurophysiological investigation of deafferentation pain. In: Bonica JJ, Lindblom U, Iggo A, editors. Advances in pain research and therapy. Vol. 5. New York: Raven Press; 1983. p. 713-38.

2. Cousins M. Acute and postoperative pain. In: Wall PD, Melzack R, editors. Textbook of pain. 3rd ed. EdinburghLondon: Churchill Livingstone; 1994. p. 357-85.

3. Katz J, Jackson M, Kavanagh BP, Sandler AN. Acute pain 
after thoracic surgery predicts long-term post-thoracotomy pain. Clin J Pain 1997;12:50-5.

4. Benedetti F, Amanzio M, Casadio C, Filosso PL, Molinatti M, Oliaro A, et al. Postoperative pain and superficial abdominal reflexes after posterolateral thoracotomy. Ann Thorac Surg 1997;64:207-10.

5. Benedetti F, Amanzio M, Casadio C, Cavallo A, Cianci R, Giobbe R, et al. Control of postoperative pain by transcutaneous electrical nerve stimulation after thoracic operations. Ann Thorac Surg 1997;63:773-6.

6. Hazelrigg SR, Landreneau RJ, Boley TM, Priesmeyer M, Schmaltz RA, Nawarawong W, et al. The effect of musclesparing versus standard posterolateral thoracotomy on pulmonary function, muscle strength, and postoperative pain. J Thorac Cardiovasc Surg 1991;101:394-401.

7. Baeza OR, Foster ED. Vertical axillary thoracotomy: a functional and cosmetically appealing incision. Ann Thorac Surg 1988;123:113-4.

8. Bethencourt DM, Holmes EC. Muscle-sparing posterolateral thoracotomy. Ann Thorac Surg 1988;45:337-9.

9. Heitmiller RF, Mathisen DJ. French incision. In: Current therapy in cardiothoracic surgery. Philadelphia: BC Decker; 1989. p. 268-9.

10. Horowitz MD, Ancalmo N, Ochsner JL. Thoracotomy through the auscultatory triangle. Ann Thorac Surg 1989;47: 782-3.

11. Mitchell R, Angell W, Wuerflein R, Dor V. Simplified lateral chest incision for most thoracotomies other than sternotomy. Ann Thorac Surg 1976;22:284-6.

12. Nazavian J, Down G, Lau OJ. Thoracotomy through the triangle of auscultation for treatment of recurrent pneumothorax in younger patients. Arch Surg 1988;123:113-4.

13. Mitchell RL. The lateral limited thoracotomy incision: standard for pulmonary operations. J Thorac Cardiovasc Surg 1990;99:590-6.
14. Kanner R, Martini N, Foley KM. Nature and incidence of postthoracotomy pain. Proc Am Soc Clin Oncol 1982;1:590.

15. Arnér S, Meyerson BA. Lack of analgesic effect of opioids on neuropathic and idiopathic forms of pain. Pain 1988;33:11-23.

16. Max MB, Schafer SC, Culnane M, Dubner R, Gracely RH. Association of pain relief with drug side effects in postherpetic neuralgia: a single dose study of clonidine, codeine, ibuprofen and placebo. Clin Pharmacol Ther 1988;43:363-71.

17. Kupers RC, Konings H, Adriasen H, Gybels JM. Morphine differentially affects the sensory and affective ratings in neurogenic and idiopathic forms of pain. Pain 1991;47:5-12.

18. Portenoy RK, Foley KM. Chronic use of opioid analgesics in non-malignant pain: report of 38 cases. Pain 1986;25:171-86.

19. Portenoy RK, Foley KM, Inturrisi CE. The nature of opioid responsiveness and its implications for neuropathic pain: new hypotheses derived from studies of opioid infusions. Pain 1990;43:273-86

20. Rowbotham MC, Reisner LM, Fields IlL. Both intravenous lidocaine and morphine reduce the pain of post-herpetic neuralgia. Neurology 1991;41:1024-8.

21. Jadad AR, Carroll D, Glynn CJ, Moore RA, McQuay HJ. Morphine responsiveness of chronic pain: double-blind randomised crossover study with patient-controlled analgesia. Lancet 1992;339:1367-71.

22. Benedetti F, Vighetti S, Amanzio M, Casadio C, Oliaro A, Bergamasco B, et al. Dose-response relationship of opioids in nociceptive and neuropathic postoperative pain. Pain 1998. In press.

23. Fields HL. Peripheral neuropathic pain: an approach to management. In: Wall PD, Melzack R, editors. Textbook of pain. 3rd ed. Edinburgh-London: Churchill Livingstone; 1994. p. 991-6.

24. Kavanagh BP, Katz J, Sandler AN. Pain control after thoracic surgery: a review of current techniques. Anesthesiology 1994; 81:737-59.

\section{Availability of Journal back issues}

As a service to our subscribers, copies of back issues of The Journal of Thoracic and Cardiovascular Surgery for the preceding 5 years are maintained and are available for purchase from Mosby at a cost of $\$ 16.00$ per issue until inventory is depleted. The following quantity discounts are available: $25 \%$ off on quantities of 12 to 23 , and one third off on quantities of 24 or more. Please write to Mosby, Inc., Subscription Services, 11830 Westline Industrial Drive, St. Louis MO 63146-3318, or call 800-453-4351 or 314-453-4351 for information on availability of particular issues. If unavailable from the publisher, photocopies of complete issues may be purchased from UMI, 300 N. Zeeb Rd., Ann Arbor, MI 48106, 313-761-4700. 